\title{
PERAN INVESTASI TERHADAP PEREKONOMIAN DAERAH : STUDI KASUS DI KABUPATEN GARUT
}

\author{
Rahmawatin ${ }^{1}$ \\ Bayu Kharisma \\ Fakultas Ekonomi dan Bisnis Universitas Padjadjaran, Jawa Barat, Indonesia ${ }^{1,2}$ \\ Email: bayu.kharisma@unpad.ac.id
}

\begin{abstract}
High economic growth shows an increase in productivity, the impact of which can increase employment opportunities. Besides increasing productivity can also increase community income, reduce unemployment and reduce poverty. One component of economic growth is investment, which is needed to increase productivity. The aims of this paper was to determine the description or condition of the investment climate in Garut Regency viewed from the ICOR value coefficient. The results showed that the ICOR value illustrates the efficiency of investment in an area. The ICOR value of Garut Regency in 2018 is 5.7. By using the standard method, the results show that investment in Garut Regency needs lag $(t+4)$ so that an investment reaches full capacity.
\end{abstract}

Keywords: Garut Regency; ICOR; Investment; GRDP.

\begin{abstract}
ABSTRAK
Pertumbuhan ekonomi yang tinggi menunjukkan terjadinya peningkatan produktivitas, yang dampaknya dapat menambah kesempatan kerja. Selain itu peningkatan produktivitas juga dapat meningkatkan pendapatan masyarakat, mengurangi pengangguran dan mengurangi kemiskinan. Salah satu komponen dalam pertumbuhan ekonomi adalah investasi, yang diperlukan untuk meningkatkan produktivitas. Tujuan penelitian ini adalah mengetahui gambaran atau kondisi iklim investasi di Kabupaten Garut dilihat dari koefisien nilai ICOR. Hasil penelitian menunjukkan bahwa nilai ICOR menggambarkan efisiensi investasi di suatu wilayah. Nilai ICOR Kabupaten Garut pada tahun 2018 adalah 5,7. Dengan menggunakan metode standar didapatkan hasil bahwa investasi di Kabupaten Garut butuh lag ( $(+4)$ agar suatu investasi mencapai full capacity.
\end{abstract}

Kata Kunci : Kabupaten Garut; ICOR; Investasi; PDRB. 


\section{PENDAHULUAN}

Investasi merupakan pembelian barang yang tidak dikonsumsi tetapi digunakan untuk modal dalam kegiatan produksi yang akan menghasilkan barang dan jasa dimasa yang akan datang. Peningkatan investasi diyakini memiliki konstribusi sebagai pengungkit untuk meningkatkan pertumbuhan ekonomi (Iriawan, 2010). Dalam ekonomi makro, investasi juga berperan sebagai salah satu komponen dari pendapatan nasional, atau Produk Domestik Regional Bruto (PDRB) bagi pendapatan regional (Mankiw, 2016).

Selama ini pertumbuhan ekonomi lebih banyak ditopang oleh konsumsi rumah tangga (lebih dari 50 persen), sehingga lesunya daya beli masyarakat sangat mempengaruhi kondisi perekonomian. Oleh karena itu, konstribusi investasi perlu diperbesar untuk menyerap tenaga kerja dan akhirnya dapat mendorong pertumbuhan ekonomi. Presiden Joko Widodo mengatakan bahwa kunci pertumbuhan ekonomi nasional terletak pada nilai ekspor dan investasi. Pemerintah juga berupaya untuk menggeser pertumbuhan yang sangat bergantung dari konsumsi. "Kita memang ingin menggeser dari pertumbuhan yang ketergantungannya kepada konsumsi menjadi pertumbuhan yang lebih berkualitas. Geser ke arah-arah yang produktif ke arah produksi,” (presidenri.go.id).

Tabel 1.

Indikator Kinerja Investasi Kabupaten Garut, 2019 - 2024

\begin{tabular}{lccccc}
\hline \multirow{2}{*}{ Indikator Sasaran } & \multirow{2}{*}{ Satuan } & \multicolumn{3}{c}{ Kondisi awal } & \multicolumn{2}{c}{ Target } \\
\cline { 3 - 6 } & & $\mathbf{2 0 1 8}$ & $\mathbf{2 0 1 9}$ & $\mathbf{2 0 2 1}$ & $\mathbf{2 0 2 4}$ \\
\hline $\begin{array}{l}\text { Jumlah Investasi Berskala Nasional } \\
\text { (PMDN/ PMA) }\end{array}$ & $\begin{array}{c}\text { Triliun } \\
\text { Rp }\end{array}$ & 1.31 & 1.41 & 1.86 & 2.26 \\
\hline
\end{tabular}

Sumber: Bappeda Kab. Garut, 2019 
Untuk mewujudkan visi RPJMD Kabupaten Garut 2019-2024 yaitu, GARUT YANG BERTAQWA, MAJU DAN SEJAHTERA. Salah satu misi yang ingin dicapai adalah meningkatkan kemandirian ekonomi masyarakat berbasis potensi lokal dan industri pertanian serta pariwisata yang berdaya saing disertai pengelolaan sumber daya alam secara berkelanjutan, dengan tujuan meningkatnya perekonomian daerah yang berkualitas dan berdaya saing. Lebih lanjut sasaran yang ingin dicapai sebagai prioritas pembangunan daerah salah satunya adalah meningkatnya realisasi investasi daerah. Target jumlah investasi berskala nasional (PMDN/PMA) yang ingin dicapai sebesar Rp 2,26 Triliun pada 2024.

Incremental Capital Output Ratio (ICOR) merupakan salah satu indikator makro ekonomi yang dapat memberikan gambaran mengenai investasi. Nilai ICOR ini dapat digunakan untuk melihat produktivitas dan efisiensi dari investasi yang telah dilakukan suatu daerah. Penelitian mengenai nilai ICOR telah banyak dilakukan diantaranya oleh Iriawan(2010), BPS(2004) dan BPS Kab. Lumajang(2017).

Estimasi kebutuhan investasi suatu daerah menjadi sangat penting mengingat pentingnya peranan investasi bagi pembangunan ekonomi. Perencanaan dan evaluasi dibutuhkan agar pengambil kebijakan dapat menentukan arah pembangunan dengan jelas dan terarah. Nilai ICOR dapat digunakan untuk mengestimasi kebutuhan investasi yang diperlukan suatu wiayah untuk mencpai tingkat pertumbuhan ekonomi tertentu pada masa yang akan datang, dan penting untuk kegiatan perencanaan ekonomi suatu wilayah (Setiyanto, 2015). 
Tabel 2.

Data Minat Investasi di Kabupaten Garut Berdasarkan

Sektor Usaha, Tahun 2017

\begin{tabular}{lcc}
\hline & Sektor & Nilai (Miliar \\
& $(\mathbf{1})$ & $(\mathbf{2})$ \\
\hline & & 252.440 \\
\hline Sektor Primer & 608.205 \\
Sektor Sekunder & 2.776 .100 \\
Sektor Tersier & 3.636 .746 \\
\hline Jumlah & \\
\hline
\end{tabular}

Sumber : DPMPT Kab.Garut, 2017

Bila melihat data minat investasi berdasarkan sektor di Kabupaten Garut pada tahun 2017, minat investor untuk berinvestasi cukup besar yaitu mencapai 3,6 T. Pemerintah daerah perlu menangkap peluang tersebut dengan melakukan perbaikan iklim investasi yang kondusif. Iklim investasi yang akan mendorong masuknya investasi yang akan meningkatkan pertumbuhan ekonomi, produktivitas dan penyerapan tenaga kerja.

Institusi yang baik harus dapat mendukung produktifitas ekonomi, seperti mengatur regulasi usaha, melindungi hak properti, membangun infrastruktur dan memberi insentif untuk meningkatkan investasi. Tidak ada jaminan perlindungan hak terhadap properti dapat mengurangi keinginan investor untuk berinvestasi. Peningkatan pertumbuhan ekonomi tidak akan terjadi, bila reformasi kelembagaan untuk membuat kualitas institusi menjadi lebih baik tidak dilakukan (Gurvich, 2016). 
Informasi mengenai potensi dan iklim investasi daerah sangat diperlukan sebagai bahan pertimbangan dalam pengambilan keputusan untuk berinvestasi, seperti kondisi makro ekonomi daerah, infrastruktur dan sosial budaya daerah. Oleh karena itu informasi mengenai hal tersebut harus tersedia. Dengan demikian, tujuan penelitian ini adalah mengetahui gambaran atau kondisi iklim investasi di Kabupaten Garut dilihat dari koefisien nilai ICOR.

Investasi didefinisikan sebagai pengeluaran untuk membeli barang modal dengan tujuan untuk meningkatkan output dalam jangka panjang. Peran investasi penting untuk meningkatkan pertumbuhan ekonomi, karena investasi merupakan komponen dari pengeluaran agrerat. Pertambahan barang modal dari investasi, akan tujuan penelitian ini adalah mengetahui gambaran atau kondisi iklim investasi di Kabupaten Garut dilihat dari koefisien nilai ICOR. menambah kapasitas memproduksi dan kesempatan kerja. Model ekonomi yang menjelaskan hubungan antara pertumbuhan output dan investasi adalah sebagai berikut (Todaro, et al., 2015) :

Salah satu model pertumbuhan Neoklasik diperkenalkan oleh Solow (1956) dan Swan (1956). Model pertumbuhan Solow menunjukkan pengaruh interaksi antara modal, tenaga kerja, dan kemajuan teknologi terhadap output yang dihasilkan. Kemajuan teknologi yang menjelaskan pertumbuhan ekonomi pada model solow dianggap sebagai faktor eksogen. Model Solow mengasumsikan bahwa ada pengembalian yang semakin berkurang (diminishing returns) dari modal 
dan tenaga kerja, dengan menggunakan fungsi produksi Cobb-Douglas dapat dijelaskan :

$\mathrm{Y}=\mathrm{K}^{\alpha}(\mathrm{AL})^{1-\alpha}$

Keterangan:

$\mathrm{Y}=\mathrm{PDB}$,

$\mathrm{K}=$ akumulasi kapital (modal manusia dan juga modal fisik),

$\mathrm{L}=$ tenaga kerja (labour),

$\mathrm{A}=$ mewakili produktivitas tenaga kerja secara eksogen.

Kemajuan teknologi dalam model Solow diasumsikan tetap, sehingga model pertumbuhan Neoklasik Solow disebut juga model pertumbuhan eksogen.

Model pertumbuhan Harrod-Domar menjelaskan hubungan ekonomi antara pertumbuhan PDB dengan tingkat tabungan bersih (net savings rate) nasional dan rasio modal-output (capital-output ratio) nasional. Capital-output ratio adalah rasio yang menunjukkan satuan modal yang diperlukan untuk menghasilkan unit output selama periode tertentu waktu (c). Model Harrod-Domar mengasumsikan tabungan sama dengan investasi, maka persamaan yang terbentuk adalah :

$\mathrm{S}=\mathrm{sY}=\mathrm{c} \Delta \mathrm{Y}=\Delta \mathrm{K}=\mathrm{I}$

disederhanakan menjadi,

$\mathrm{s} \mathrm{Y}=\mathrm{c} \Delta \mathrm{Y}$

dengan memindahkan kedua sisi pada persamaan (3), maka didapatkan

$\frac{\Delta Y}{Y}=\frac{s}{c}$

persamaan (4) merupakan versi sederhana dari model pertumbuhan Harrod-Domar, dimana $\Delta \mathrm{Y} / \mathrm{Y}$ menggambarkan pertumbuhan ekonomi. Model pertumbuhan Harrod-Domar bergantung pada net savings rate (s) nasional dan berbanding terbalik dengan capital-output ratio (c) nasional (Todaro, et al., 2015). 
Konsep ICOR atau sering juga disebut koefisien modal menunjukkan hubungan antara besarnya investasi (modal) dan nilai output. Konsep ICOR tersebut dikenal melalui teori yang dikemukakan oleh Harrod-Domar (susilowati, 2012). Berdasarkan konsep tersebut nilai ICOR dapat diformulasikan sebagai berikut,

$\mathrm{ICOR}=\Delta \mathrm{K} / \Delta \mathrm{Y}$

Formula diatas menunjukkan rasio antara perubahan kapital $(\Delta \mathrm{K})$ dan perubahan output $(\Delta Y)$. Dari metode (1) didapatkan pengertian bahwa ICOR menunjukkan perbandingan antara kenaikan tertentu pada stok modal dibandingkan dengan kenaikan output atau pendapatan. Lebih lanjut nilai ICOR yang dihitung dengan menggunakan rata - rata juga dapat menunjukkan hubungan antara stok modal yang ada dan aliran output lancar yang dihasilkan atau dengan kata lain menunjukkan hubungan antara segala sesuatu yang telah diinvestasikan pada masa lalu dengan keseluruhan pendapatan. Dengan memodifikasi penambahan barang modal baru atau perubahan stok kapital $(\Delta K)$ menjadi Investasi $(I)$, sehingga metode penghitungan ICOR menjadi:

$\mathrm{ICOR}=\mathrm{I} / \Delta \mathrm{Y}$

Hasil ICOR metode (2) akan menghasilkan penghitungan banyaknya kebutuhan investasi yang diperlukan untuk mendapatkan 1 unit output. Sebagai contoh, investasi yang ditanamkan di wilayah A pada tahun t sebesar Rp150 miliar, dan menghasilkan tambahan output sebesar Rp 25 miliar, maka nilai ICOR wilayah A adalah sebesar 6 (150 miliar / 25 miliar). Angka ini menunjukkan bahwa untuk menaikkan 1 unit output diperlukan investasi sebesar 6 unit. Tambahan output tidak 
hanya berasal dari investasi, tetapi juga dari faktor lain seperti tenaga kerja, teknologi dan entrepreneurship. Oleh karena itu peranan faktor lain selain investasi diasumsikan konstan (ceteris paribus)

Secara umum kapital atau yang sering disebut sebagai "Gross Capital Stock" merupakan akumulasi atau penumpukan pembentukan modal bruto dari tahun ke tahun yang digunakan untuk menghasilkan produk baru. Kapital secara fisik adalah seluruh barang modal yang digunakan dalam proses produksi seperti mesin, bangunan, kendaraan dan lainnya. Dalam sistem pembukuan neraca perusahaan, yang dimaksud dengan kapital adalah harta tetap (fixed assests) suatu badan usaha (BPS Kab.Bandung, 2008).

PMTB didefinisikan sebagai penambahan dan pengurangan aset tetap (fixed asset) pada suatu unit produksi. Secara garis besar aset tetap dapat diklasifikasikan menurut jenis barang modal seperti: bangunan dan kosntruksi lain, mesin dan perlengkapan, kendaraan, tumbuhan, ternak dan barang modal lainnya. PMTB mencakup pengadaan, pembuatan dan pembelian barang modal baru dari dalam negeri dan pembuatan dan pembelian barang modal baru maupun bekas dari luar negeri. Termasuk dalam PMTB ini adalah perbaikan besar barang modal yang mengakibatkan penambahan umur pemakaian atau meningkatkan kemampuan barang modal tersebut, dikurangi dengan penjualan barang modal bekas (BPS Kab.Lumajang, 2017). Ciri-ciri barang modal adalah; dapat digunakan lebih dari 1 tahun, bernilai relatif besar, dapat digunakan berulangkali di dalam proses produksi dan bermanfaat dalam jangka panjang. 
PMTB menurut wujud barang modal adalah; 1). Bangunan / konstruksi. 2). Mesin dan perlengkapan lainnya. 2). Perluasan perkebunan dan tanaman baru. 3). Penambahan ternak yang memproduksi susu dan bulu, atau yang dimanfaatkan tenaganya, kecuali ternak potong. 4). Pembentukan modal dalam bentuk makelar service charge dan ongkos pemindahan hak milik dalam transaksi jual beli tanah, sumber mineral, hak pengusahaan hutan, hak paten, hak cipta, serta pembelian barang modal bekas dari luar wilayah / luar negeri.

Output adalah hasil yang diperoleh dari faktor produksi yang digunakan baik dalam bentuk barang atau jasa seperti tanah, tenaga kerja, modal dan kewiraswastaan. Output dalam konsep ekonomi nasional merupakan nilai dari seluruh barang dan jasa yang dihasilkan oleh faktor domestik dalam suatu periode tertentu. Output yang dihasilkan perusahan mencakup nilai barang jadi yang dihasilkan selama suatu periode tertentu ditambah nilai perubahan stok barang yang masih dalam proses. Output dalam penghitungan ICOR adalah tambahan (flow) produk dari hasil kegiatan ekonomi dalam suatu periode. Output ini merupakan seluruh nilai tambah atas dasar biaya faktor produksi yang dihasilkan dari seluruh kegiatan usaha. Konsep output dalam penghitungan ICOR ini mengunakan konsep nilai tambah (BPS Kab.Situbondo, 2012).

Nilai tambah adalah suatu tambahan nilai dari input antara yang digunakan dalam proses menghasilkan barang/jasa. Penambahan nilai input antara ini terjadi karena input antara tersebut telah mengalami proses produksi yang mengubahnya menjadi barang yang nilainya lebih tinggi. Input antara sendiri mencakup nilai seluruh komoditi yang habis atau dianggap habis dalam suatu proses produksi, 
seperti: bahan baku, bahan bakar, pemakaian listrik dan sebagainya. Barang yang digunakan sebagai alat dalam suatu proses produksi dan umurnya kurang dari setahun dan habis dipakai dimasukkan sebagai input antara bukan barang modal.

Nilai tambah bisa berupa nilai tambah bruto maupun nilai tambah neto. Nilai tambah bruto dari suatu unit produksi dihitung dari output bruto atas harga produsen dikurangi input antara atas dasar harga pasar. Sedangkan nilai tambah neto atas harga pasar dihitung dari nilai tambah bruto atas harga pasar dikurangi pajak tak langsung dan penyusutan. Karena keterbatasan data penyusutan dan pajak tak langsung, maka konsep nilai tambah yang digunakan dalam penghitungan ICOR dalam penelitian ini adalah nilai tambah bruto atas dasar harga pasar yang terdapat pada nilai PDRB (BPS Kota Yogyakarta, 2017).

Penghitungan ICOR pada penelitian ini menggunakan konsep investasi yang mengacu pada konsep ekonomi nasional. Pengertian investasi dalam konsep ekonomi nasional yang mengacu pada A System of National Account adalah selisih antara stok kapital pada tahun (t) dikurangi dengan stok kapital pada tahun (t-1). Sehingga setiap terjadi penambahan kapital (modal) selalu dianggap sebagai investasi. Oleh karena itu besarnya investasi secara fisik yang direlisasikan pada suatu tahun tertentu dicerminkan oleh besarnya PMTB (BPS Kota Semarang, 2011). Dengan mengasumsikan $\Delta \mathrm{K}=\mathrm{I}$ (investasi), secara matematis metode yang digunakan untuk menghitung ICOR adalah :

$I C O R=\frac{\Delta K}{\Delta Y}=\frac{I_{t}}{\Delta Y}=\frac{I_{t}}{Y_{t}-Y_{t-1}}$

Efek dari investasi membutuhkan waktu yang cukup lama untuk dapat menghasilkan besaran output yang diinginkan. Tenggang waktu yang dibutuhkan 
untuk memperoleh tambahan output dari investasi yang dilakukan disebut lag. Dengan mempertimbangkan periode lag yang terjadi, maka untuk memperoleh suatu nilai ICOR yang mewakili dilakukan penghitungan dengan simple average (rata-rata sederhana) (BPS, 2004). Metode penghitungan ICOR ini dapat diperluas menjadi persamaan standar yang dibuat berdasarkan prinsip rata-rata sederhana. Metode dalam persamaan (8) mengasumsikan bahwa penambahan output pada tahun tertentu terjadi karena adanya investasi yang dilakukan pada tahun tersebut. Metode ICOR $_{1-5}$ menghitung investasi yang dilakukan pada tahun ke-t $\left(\mathrm{I}_{\mathrm{t}}\right)$ akan menghasilkan output pada tahun ke-t $\left(\mathrm{ICOR}_{1}\right)$ hingga tahun ke-(t+4) pada ICOR 5 . Pada $\mathrm{ICOR}_{1}$ tidak ada lag waktu sampai investasi dapat memberikan tambahan output, sedangkan pada $\mathrm{ICOR}_{2-5}$ menghitung lag waktu dari tahun ke-(t+1) hingga tahun ke-(t+4).

$\operatorname{ICOR}_{1-5}=\frac{1}{n} \sum_{t_{1}}^{t_{n}} \frac{I_{t}}{Y_{t+p}-Y_{t+p-1}}$

Metode lain yang digunakan dalam penghitungan ICOR adalah dengan memodifikasi investasi $\left(\mathrm{I}_{\mathrm{t}}\right)$ menjadi bagian dari investasi pada tahun sebelumnya yaitu tahun ke-(t-1) dan tahun ke-(t). Modifikasi ini dapat dilihat dalam persamaan (9). Asumsi yang digunakan adalah tambahan output pada tahun tertentu merupakan hasil penanaman investasi tahun ke-t dan tahun ke-(t-1) dengan proporsi 0,1 untuk tahun ke-(t-1) dan 0,9 untuk tahun ke-t. Investasi yang ditanamkan pada tahun ke-(t-1) diasumsikan belum memberikan hasil secara optimal, maka investasi itu akan memberikan tambahan output pada tahun berikutnya.

$\operatorname{ICOR}_{6-10}=\frac{1}{n} \sum_{t_{1}}^{t_{n}} \frac{0,1 I_{t-1}+0,9 I_{t}}{Y_{t+p}-Y_{t+p-1}}$ 
Metode ICOR $_{6-10}$ berarti bahwa selain investasi yang ditanamkan pada tahun ke $t$, investasi yang ditanamkan pada tahun ke-(t-1) masih mempunyai kontribusi pada tambahan output tahun ke-t. Hal ini terjadi karena investasi tahun ke-(t-1) tidak full capacity, sehingga ketika pada tahun ke-t mencapai full capacity $\mathrm{I}_{(\mathrm{t}-1)}$ tersebut bisa menambah output pada tahun ke-t hingga tahun ke-(t+4). Modifikasi Metode ICOR berikutnya adalah dengan memodifikasi investasi menjadi bagianbagian investasi dari tahun ke-(t-2), ke-(t-1) dan ke-t. Metode ini dapat dilihat pada persamaan (10).

$I C O R_{11-15}=\frac{1}{n} \sum_{t_{1}}^{t_{n}} \frac{0,1 I_{t-2}+0,2 I_{t-1}+0,7 I_{t}}{Y_{t+p}-Y_{t+p-1}}$

Pada metode ICOR $_{11-15}$ ini diasumsikan bahwa pertambahan output tahun tertentu merupakan hasil dari investasi pada tiga tahun berturut-turut dengan proporsi 0,1 untuk tahun ke-(t-2), proporsi 0,2 untuk tahun ke-(t-1) dan proporsi 0,7 untuk tahun ke-t. Pada Metode ini tambahan output pada tahun ke t juga dipengaruhi oleh investasi yang ditanamkan pada tahun ke-(t-1) dan tahun ke-(t-2), selain itu masih berkontribusi pada tahun ke-t hingga tahun ke- $(\mathrm{t}+4)$.

Penghitungan dengan metode standar di atas menerapkan prinsip rata-rata sederhana sehingga dimungkinkan terjadinya bias yang disebabkan karena fluktuasi yang cukup ekstrim pada tahun tertentu. Sebagai pembanding dilakukan juga penghitungan ICOR menggunakan metode akumulasi investasi yang menerapkan prinsip rata-rata tertimbang.

$$
\operatorname{ICOR}_{t-t_{n}}=\frac{\sum_{t}^{t_{n-1}} I_{t}}{Y_{n}-Y_{t+1}}
$$


Melalui metode akumulasi dapat dilihat sejauh mana investasi yang ditanamkan sejak tahun ke-t sampai tahun ke- $\mathrm{t}_{\mathrm{n}-1}$ dapat berpengaruh terhadap penambahan output sejak tahun ke-(t+1) sampai tahun ke-n.

\section{HASIL DAN PEMBAHASAN}

Kabupaten Garut terletak di bagian selatan Provinsi Jawa Barat, memiliki luas wilayah sebesar 307.407 Ha atau 8,2 persen dari luas Provinsi Jawa Barat. Berikut ini beberapa indikator ekonomi Kabupaten Garut.

Tabel 3.

Indikator Ekonomi Kabupaten Garut

\begin{tabular}{lcccc}
\hline & Indikator & $\mathbf{2 0 1 6}$ & $\mathbf{2 0 1 7}$ & $\mathbf{2 0 1 8}$ \\
& $(\mathbf{1})$ & $\mathbf{( 2 )}$ & $\mathbf{( 3 )}$ & $\mathbf{( 4 )}$ \\
\hline PDRB ADHB (Miliar Rp) & 44.452 & 48.004 & 53.009 \\
PDRB per Kapita (Juta Rp) & 17.300 & 18.543 & 20.338 \\
PDRB ADHK (Miliar Rp) & 33.804 & 35.465 & 37.224 \\
Laju Pertumbuhan & 5,9 & 4,91 & 4,96 \\
Share PMTB thd PDRB (\%) & 26,65 & 26,66 & 26,41 \\
\hline S & & & & \\
\hline
\end{tabular}

Sumber : BPS, diolah, 2019

Penduduk Kabupaten Garut pada tahun 2018 berjumlah 2,6 juta jiwa, dengan pendapatan perkapita sebesar 20,3 juta per tahun. Rendahnya pendapatan per kapita Kabupaten Garut bila dibandingkan dengan angka Provinsi Jawa Barat yaitu sebesar 40,31 juta per tahun, menjadi salah satu tantangan pembangunan di 
Kabupaten Garut. Selain itu tantangan pembangunan daerah yang lainnya adalah masalah pengangguran dan kemiskinan.

PDRB atas dasar harga konstan (ADHK) Kabupaten Garut pada tahun 2018 sebesar 37,2 miliar Rupiah, meningkat 4,96 persen dibandingkan dengan tahun sebelumnya. Laju pertumbuhan ekonomi Kabupaten Garut selama tiga tahun terakhir cenderung melambat. Bila dibandingkan dengan laju pertumbuhan ekonomi nasional dan Jawa Barat, laju pertumbuhan ekonomi Kabupaten Garut pada tahun 2018 lebih rendah.

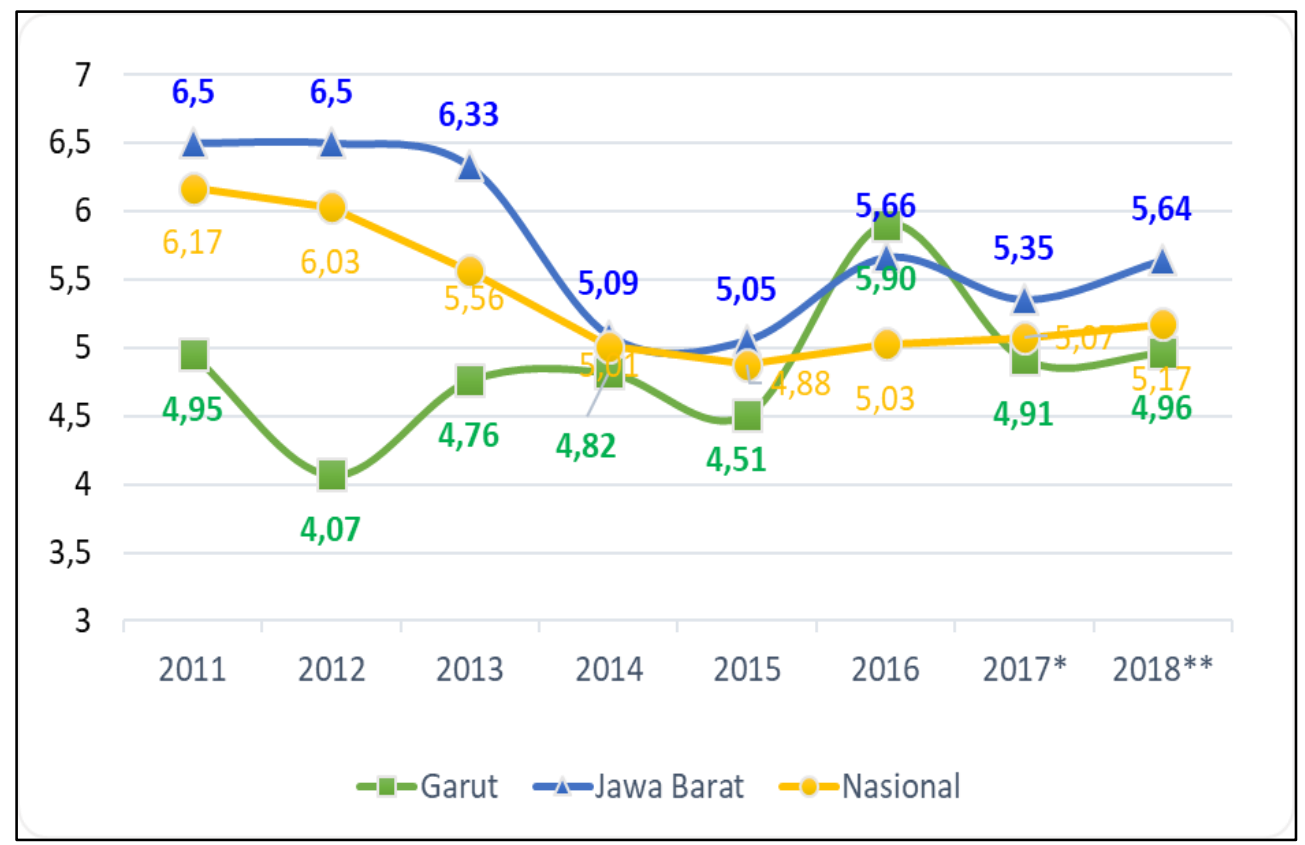

Sumber : BPS, diolah

\section{Grafik 1.}

Perbandingan Laju Pertumbuhan Ekonomi Nasional, Jawa Barat dan Garut, Tahun 2011-2018

Pengembangan sektor ekonomi unggulan perlu dilakukan untuk meningkatkan pendapatan masyarakat dan membuka lapangan pekerjaan, sebagai solusi menghadapi tantangan pembangunan daerah. 
Tabel 4.

Potensi Indutri Komoditi Unggulan Kabupaten Garut

\begin{tabular}{|c|c|c|c|}
\hline Industri & $\begin{array}{c}\text { Unit } \\
\text { Usaha }\end{array}$ & $\begin{array}{c}\text { Tenaga } \\
\text { Kerja }\end{array}$ & $\begin{array}{c}\text { Penjualan/ } \\
\text { Tahun }\end{array}$ \\
\hline Akar Wangi & 6 & 126 & $5 \mathrm{M}$ \\
\hline Sutera Alam & 10 & 250 & $10 \mathrm{M}$ \\
\hline Batik & 12 & 200 & $10 \mathrm{M}$ \\
\hline Kulit & 171 & 750 & $33,45 \mathrm{M}$ \\
\hline Bambu & 1.998 & 6.077 & $42,8 \mathrm{M}$ \\
\hline
\end{tabular}

Sumber: BAPPEDA Kab. Garut

Sektor pertanian merupakan sektor ekonomi unggulan, sebagai penyumbang terbesar perekonomian Kabupaten Garut sebesar 37,69 persen. Selain itu, sektor perdagangan dan industri merupakan tiga besar penyumbang PDRB Kabupaten Garut.

Asumsi bahwa investasi yang ditanamkan pada tahun ke-t $\left(\mathrm{I}_{\mathrm{t}}\right)$ akan menghasilkan output pada tahun ke-t juga, maka dapat dihitung nilai ICOR nasional, Provinsi Jawa Barat, dan Kabupaten Garut per tahun. Bila dibandingkan dengan nilai ICOR nasional dan Provinsi Jawa Barat selama satu windu terakhir, maka nilai ICOR Kabupaten Garut cukup fluktuatif. Hasil penghitungan pada Tabel 5 bahwa nilai ICOR Kabupaten Garut pada tahun 2018 sebesar 5,7, hal ini berarti bahwa setiap penambahan 1 unit output memerlukan investasi sebesar 5,7 unit. 
Tabel 5.

Perbandingan nilai ICOR nasional, Provinsi Jawa Barat dan Kabupaten Garut, Tahun 2011 - 2018

\begin{tabular}{ccccc}
\hline Tahun & ICOR Nasional & $\begin{array}{l}\text { ICOR } \\
\text { Barat }\end{array}$ & Jawa & ICOR Garut \\
\hline $\mathbf{( 1 )}$ & $\mathbf{( 2 )}$ & $\mathbf{( 3 )}$ & $\mathbf{( 4 )}$ \\
\hline 2011 & 5,47 & 4,16 & 5.82 \\
2012 & 5,75 & 4,32 & 7.37 \\
2013 & 6,18 & 4,12 & 5.77 \\
2014 & 6,79 & 5,16 & 5.84 \\
2015 & 6,97 & 5,16 & 6.18 \\
2016 & 6,73 & 4,58 & 4.78 \\
2017 & 6,75 & 4,88 & 5.69 \\
2018 & 6,72 & 4,65 & 5.70 \\
\hline
\end{tabular}

Sumber : BPS, diolah

Investasi bersifat jangka panjang, sehingga investasi yang ditanamkan pada tahun tertentu belum dapat langsung memberikan kontribusi pada pertumbuhan ekonomi secara keseluruhan. Sebaliknya pertumbuhan ekonomi pada tahun tertentu, bisa disebabkan oleh penanaman investasi yang dilakukan pada tahun sebelumnya. Hal ini berarti untuk mendapatkan hasil investasi yang optimal dibutuhkan lag waktu.

Berdasarkan hasil penghitungan nilai ICOR Kabupaten Garut dengan menggunakan metode standar, seperti yang terlihat pada tabel 3 . ICOR 15 menunjukan nilai ICOR terkecil Selama tahun 2016 hingga 2018. Metode ICOR $_{15}$ dihitung berdasarkan Lag-4 ini mempunyai nilai terendah. 
Tabel 6.

Nilai ICOR metode standar Kabupaten Garut, 2016 - 2018

\begin{tabular}{cccc}
\hline \hline Metode Standar & $\mathbf{2 0 1 6}$ & $\mathbf{2 0 1 7}$ & $\mathbf{2 0 1 8}$ \\
\hline ICOR 1 & $(2)$ & $(3)$ & $(4)$ \\
ICOR 2 & 5.96 & 5.92 & 5.89 \\
ICOR 3 & 5.74 & 5.69 & 5.64 \\
ICOR 4 & 5.29 & 5.26 & 5.23 \\
ICOR 5 & 5.04 & 5.01 & 4.98 \\
ICOR 6 & 4.80 & 4.73 & 4.71 \\
ICOR 7 & 5.93 & 5.89 & 5.86 \\
ICOR 8 & 5.71 & 5.66 & 5.61 \\
ICOR 9 & 5.26 & 5.23 & 5.21 \\
ICOR 10 & 5.01 & 4.98 & 4.95 \\
ICOR 11 & 4.75 & 4.70 & 4.69 \\
ICOR 12 & 5.88 & 5.83 & 5.80 \\
ICOR 13 & 5.40 & 5.39 & 5.37 \\
ICOR 14 & 5.12 & 5.10 & 5.08 \\
ICOR 15 & 4.85 & 4.85 & 4.83 \\
& 4.11 & 4.36 & 4.44 \\
\hline
\end{tabular}

Sumber : BPS, diolah

Besaran koefisien ICOR menggambarkan produktivitas dari penggunaan barang modal untuk meningkatkan pertumbuhan ekonomi sesuai target yang diinginkan. Semakin kecil koefisien ICOR menunjukkan semakin efisien pembentukan modal yang terjadi. Metode $\mathrm{ICOR}_{15}$ mengasumsikan bahwa pertambahan output tahun tertentu merupakan hasil dari investasi pada tiga tahun berturut-turut, dan masih berkontribusi pada tahun ke-(t+4). Hal ini menunjukkan butuh lag waktu yang cukup lama agar suatu investasi mencapai full capacity.

Hasil penghitungan nilai ICOR menggunakan metode akumulasi, angka yang dihasilkan cenderung stabil. Pada metode akumulasi ini, baik investasi maupun 
tambahan output merupakan akumulasi selama periode 2010- 2016, periode 20102017, dan periode 2010- 2018

Tabel 7.

Nilai ICOR Metode Akumulasi Kabupaten Garut

\begin{tabular}{cc}
\hline Metode Akumulasi & ICOR \\
\hline$(1)$ & $(2)$ \\
\hline Periode $2010-2016$ & 6.54 \\
Periode $2010-2017$ & 6.32 \\
Periode $2010-2018$ & 6.16 \\
\hline
\end{tabular}

Sumber : BPS, diolah

Besaran koefisien ICOR Kabupaten Garut secara total dengan metode akumulasi selama periode 2010-2018 mencapai 6,16, hal ini menggambarkan untuk memperoleh penambahan satu unit output dalam rentang periode tersebut dibutuhkan tambahan investasi fisik (PMTB) sebanyak 6,16 unit.

\section{SIMPULAN DAN SARAN}

PDRB Kabupaten Garut secara nominal mengalami peningkatan, pada tahun 2016 sebesar 44.452 miliar rupiah menjadi 53.009 miliar rupiah pada 2018. Namun laju Pertumbuhan ekonomi mengalami tren perlambatan dari sebesar 5,9 pada tahun 2016 menjadi 4,96 pada tahun 2018. Peran PMTB pada PDRB Kabupaten Garut pada tahun 2018 sebesar 26,41 persen. Nilai ICOR Kabupaten Garut pada tahun 2018 sebesar 5,7. Metode ICOR $_{15}$ menggunakan metode standar dihitung berdasarkan Lag-4 mempunyai nilai terendah. Nilai ICOR dengan metode akumulasi selama periode 2010-2018 sebesar 6,16. 
Tantangan utama investasi di Kabupaten Garut pada umumnya adalah korupsi dan birokrasi yang tidak efisien. Hasil dari penghitungan nilai ICOR Kabupaten Garut juga masih tinggi, hal tersebut menunjukkan investasi di wilayah tersebut belum efisien. Perlu dirumuskan paket kebijakan untuk memperbaiki iklim investasi di Kabupaten Garut, seperti menurunkan lama proses mengurus perijinan dan mengurangi biaya transaksi. Lebih lanjut perlu dilakukan analisis secara geografis, agar dapat dilakukan penyelarasan kebijakan antara sektoral dan kewilayahan.

\section{REFERENSI}

BPS. (2004). Incremental Capital Output Ratio Sektor Industri Pengolahan, 19902002: Jakarta

BPS. (2019). Produk Domestik Bruto Indonesia Menurut Pengeluaran Tahun 20142018: Jakarta

BPS Kabupaten Bandung. 2008. ICOR

Kabupaten Bandung (2008). Bandung: kerjasama BAPPEDA dan BPS Kabupaten Bandung

BPS Kota Semarang. (2011). Incremental Capital Output Ratio (ICOR) Kota Semarang Tahun 2010. Semarang: kerjasama BAPPEDA dan BPS Kota Semarang

BPS Kabupaten Situbondo. (2012). Incremental Capital Output Ratio (ICOR) dan Incremental Labor Output Ratio (ILOR) Kabupaten Situbondo Tahun 2011. Situbondo: kerjasama BAPPEDA dan BPS Kabupaten Situbondo.

BPS Kabupaten Lumajang. (2017). Incremental Capital Output Ratio (ICOR) Kabupaten Lumajang Tahun 2017. Lumajang: kerjasama BAPPEDA dan BPS Kabupaten Lumajang

BPS Kota Yogyakarta. (2017). ICOR Kota Yogyakarta 2016. Yogyakarta: kerjasama BAPPEDA dan BPS Kota Yogyakarta 
BPS Jawa Barat. (2019). Produk Domestik Regional Bruto Kabupaten Garut Menurut Pengeluaran 2014-2018. Bandung

Gurvich, E. (2016). "Institutional constraints and economic development". Russian Journal of Economics 2, pp.349-374.

Irawan, Yeni. (2010). Analisis Incremental Capital Output Ratio di Provinsi Sumatera Utara Jurnal Ekonomi dan Bisnis Vol.9 No.2

Mankiw, N. G. (2016). "Macroeconomics" (ninth ed.). Worth Publishers.

Setiyanto, Adi. (2015). ICOR Sektor Pertanian sebagai Basis Arah Investasi dalam Pembangunan Pertanian Berbasis Kabupaten/Kota di Indonesia. Analisis Kebijakan Pertanian. Volume 13 Nomor 1: 75-108

Susilowati, et all. (2012). Estimasi Incremental Capital Output Ratio (ICOR) untuk Perencanaan investasi dalam angka pembangunan sektor Pertanian. Jurnal Agro Ekonomi Vol 30 No.2 159-182

Todaro, M. P., \& Smith, S. C. (2015). Economic Development. United States of America: Pearson Education,Inc 